\title{
Prognostic factors, failure patterns and survival analysis in patients with resectable oral squamous cell carcinoma of the tongue
}

\author{
Kanika Sharma, Parveen Ahlawat, Munish Gairola, Sarthak Tandon, \\ Nishtha Sachdeva, Muhammed Ismail Sharief \\ Department of Radiation Oncology, Rajiv Gandhi Cancer Institute and Research Centre, Rohini, New Delhi, India
}

\begin{abstract}
Purpose: There is sparse literature on treatment outcomes research on resectable oral tongue squamous cell carcinoma (OTSCC). The aim of this study was to measure the treatment outcomes, explore the failure patterns, and identify the potential clinicopathological prognostic factors affecting treatment outcomes for resectable OTSCC.

Materials and Methods: It is a retrospective analysis of 202 patients with resectable OTSCC who underwent upfront primary surgical resection followed by adjuvant radiotherapy with or without concurrent chemotherapy if indicated.

Results: The median follow-up was 35.2 months (range, 1.2 to 99.9 months). The median duration of locoregional control (LRC) was 84.9 months (95\% confidence interval, 67.3-102.4). The 3 - and 5-year LRC rate was $68.5 \%$ and $58.3 \%$, respectively. Multivariate analysis showed that increasing $\mathrm{pT}$ stage, increasing $\mathrm{pN}$ stage, and the presence of extracapsular extension (ECE) were significantly associated with poorer LRC. The median duration of overall survival (OS) was not reached at the time of analysis. The 3- and 5-year OS rate was $70.5 \%$ and $66.6 \%$, respectively. Multivariate analysis showed that increasing pT stage and the presence of ECE were significantly associated with a poorer OS.

Conclusion: Locoregional failure remains the main cause of treatment failure in resectable OTSCC. There is scope to further improve prognosis considering modest LRC and OS. Pathological T-stage, N-stage, and ECE are strong prognostic factors. Further research is required to confirm whether adjuvant therapy adds to treatment outcomes in cases with lymphovascular invasion, perineural invasion, and depth of invasion, and help clinicians tailoring adjuvant therapy.
\end{abstract}

Keywords: Head neck, Oral cancer, Tongue, Radiotherapy, Treatment outcome, Prognosis

\section{Introduction}

Incidence of oral tongue squamous cell carcinoma (OTSCC) is on rise especially in the younger population [1-3], probably due to a rise in tobacco and alcohol intake. Early stage OTSCC is treated with single modality therapy preferably surgery [4], whereas locally advanced resectable disease is treated with combined modality therapy-surgery followed by adjuvant therapy with radiotherapy (RT) or chemoradiation (CRT). Although several clinicopathological prognostic factors have been found for oral cavity squamous cell carcinoma (OCSCC), most of these have been reported in studies done on mixed

Received 27 December 2018, Revised 12 May 2019, Accepted 27 May 2019.

Correspondence: Parveen Ahlawat, Department of Radiation Oncology, Rajiv Gandhi Cancer Institute and Research Centre, Rohini, New Delhi 110085, India. Tel: +91-8130404635, Fax: +91-11-27051037, E-mail: drparveen7781@gmail.com (http:// orcid.org/0000-0001-8025-6679)

(c) This is an Open Access article distributed under the terms of the Creative Commons Attribution Non-Commercial License (http://creativecommons.org/ licenses/by-nc/4.0/) which permits unrestricted non-commercial use, distribution, and reproduction in any medium, provided the original work is properly cited.

www.e-roj.org 
patient population with all subsites of oral cavity combined $[5,6]$. Data is limited for OTSCC per se. Since OTSCC is on rise and treatment outcome of OTSCC has been found to be poorer than that of carcinoma arising from other subsites of oral cavity $[7,8]$, it is important to identify clinicopathological factors for carcinoma arising from this subsite. The aim of this study was to measure the treatment outcomes, explore the failure patterns, and identify the potential clinicopathological prognostic factors affecting treatment outcomes for resectable OTSCC.

\section{Materials and Methods}

The Institutional Ethics Committee of our institution approved the study. The inclusion criteria were patients with localized and resectable OTSCC with or without cervical nodal involvement who had undergone primary surgical resection of the primary tumor and regional lymph nodes at this institute between November 2010 and December 2016. The exclusion criteria included: an Eastern Cooperative Oncology Group performance status of $\geq 2$; neoadjuvant chemotherapy administered prior to primary surgical resection; surgical resection performed with palliative or debulking intent; recurrent head and neck malignancies; and a prior history of RT to the head and neck region. Although the American Joint Committee on Cancer (AJCC) 7th edition was used for the staging and management, AJCC 8th edition was used to analyze prognostic factors in the analysis of this study. Adjuvant RT was administered within 4 to 6 weeks from the date of surgery depending on the high-risk features recorded in the histopathological report of the resected specimen. As per institutional policy, the following were the indications for adjuvant RT: pathological T3 or T4 stage, node positivity (even a single node), positive resection margins (<1.0 mm), close surgical margins ( $\geq 1.0 \mathrm{~mm}$ to $\leq 4.0 \mathrm{~mm}$ ), perineural invasion (PNI), and lymphovascular invasion (LVI). Depth of invasion (DOI) of $>4.0 \mathrm{~mm}$ was considered as an indication for adjuvant RT depending on the individual policy of treating physicians. Concurrent chemotherapy-weekly cisplatin $\left(40.0 \mathrm{mg} / \mathrm{m}^{2}\right)$ or carboplatin (area under the curve 2) was administered to patients with positive resection margins or extracapsular extension (ECE). Whilst planning adjuvant CRT, patients were initially considered for weekly cisplatin. Those who were elderly or presumed unfit for cisplatin were administered carboplatin or cetuximab.

Patients were treated with two-dimensional conventional RT or simultaneous-integrated boost intensity-modulated
RT (SIB-IMRT). Conventional fractionation was used for all patients. For SIB-IMRT surgical bed with positive margin or nodal region with ECE were given 66 Gy. Surgical bed without positive margin or nodal regions without ECE were given $60 \mathrm{~Gy}$ in 30 fractions. Elective nodal regions were given 54 Gy in 30 fractions. When two-dimensional parallel opposed shrinking field technique was used we delivered 50 Gy in 25 fractions to elective nodal regions and boosted surgical bed without margin positive or nodal regions without ECE to $10 \mathrm{~Gy}$ in 5 fractions. Surgical bed with positive margin or nodal region with ECE was boosted to another 6 Gy in 3 fractions.

\section{Statistical analysis}

All statistical analyses were performed using statistical package for the social science system (SPSS version 20; IBM SPSS, Armonk, NY, USA), and p-value less than 0.05 was considered statistically significant. All p-values reported represent twosided tests. Baseline clinical and pathological categorical variables were expressed as frequencies along with respective percentages. The endpoints were locoregional control (LRC) and overall survival (OS), and were calculated by the KaplanMeier product-limit method. Univariate analysis of LRC and OS was performed on the following clinical and histopathological factors selected based on results from previous studies on oral cavity cancer: age, sex, addictions (tobacco smoking, tobacco chewing and/or alcohol consumption), tumor grade, pathological T (pT) stage, pathological N (pN) stage, PNI, $\mathrm{LVI}$, resection margin status, DOI, and ECE. Multivariate Cox proportional hazards regression analysis was performed to estimate the impact of known relevant prognostic factors.

\section{Results}

The medical records of 202 patients fulfilling inclusion and exclusion criteria were reviewed. Patient and disease-related characteristics are shown in Table 1. The median follow-up was 35.2 months (range, 1.2 to 99.9 months).

The median duration of LRC was 84.9 months (95\% confidence interval, 67.3-102.4). The 3- and 5-year LRC rate was $68.5 \%$ and $58.5 \%$, respectively (Fig. 1). Univariate analysis showed that increasing $\mathrm{pT}$ stage, increasing $\mathrm{pN}$ stage, and the presence of $\mathrm{PNI}, \mathrm{LVI}$, and ECE were significant poor prognostic factors for LRC. However, multivariate analysis showed that increasing pT stage, increasing pN stage, and the presence of ECE were significantly associated with poorer LRC (Table 2).

The median duration of OS was not reached at the time of analysis. The 3- and 5-year OS rate was 70.5\% and 
Table 1. Patient and disease-related characteristics

\begin{tabular}{|c|c|}
\hline Variable & Value \\
\hline Age (yr) & $54.19 \pm 14.16$ \\
\hline Median (range) & $56(23-94)$ \\
\hline$\leq 50$ & 81 (40.1) \\
\hline$>50$ & $121(59.9)$ \\
\hline \multicolumn{2}{|l|}{ Sex } \\
\hline Male & $153(75.7)$ \\
\hline Female & $49(24.3)$ \\
\hline \multicolumn{2}{|l|}{ Addictions } \\
\hline Absent & $97(48.1)$ \\
\hline Tobacco & $86(81.9)$ \\
\hline Alcohol & $32(30.5)$ \\
\hline \multicolumn{2}{|l|}{ Grade } \\
\hline Well-differentiated & $49(24.3)$ \\
\hline Moderately differentiated & $148(73.3)$ \\
\hline Poorly differentiated & $5(2.4)$ \\
\hline \multicolumn{2}{|l|}{ Type of surgery } \\
\hline Wide local excision & $32(15.8)$ \\
\hline Hemiglossectomy & $170(84.2)$ \\
\hline \multicolumn{2}{|l|}{ Type of neck dissection } \\
\hline Selective nodal dissection & $133(65.8)$ \\
\hline Modified neck dissection & $43(21.3)$ \\
\hline Radical neck dissection & $19(9.4)$ \\
\hline Not dissected & 7 (3.5) \\
\hline \multicolumn{2}{|l|}{ pT Stage } \\
\hline pT1 & 37 (18.3) \\
\hline pT2 & 101 (50.0) \\
\hline рT3 & $51(25.3)$ \\
\hline pT4a & $13(6.4)$ \\
\hline \multicolumn{2}{|l|}{ pN Stage } \\
\hline pNo & $123(60.2)$ \\
\hline pN1 & 25 (12.8) \\
\hline $\mathrm{pN} 2 \mathrm{a}$ & $10(5.0)$ \\
\hline $\mathrm{pN} 2 b$ & $9(4.5)$ \\
\hline $\mathrm{pN} 2 \mathrm{c}$ & $3(1.5)$ \\
\hline $\mathrm{pN} 3 \mathrm{~b}$ & $25(12.5)$ \\
\hline Not dissected & $7(3.5)$ \\
\hline \multicolumn{2}{|l|}{ Stage } \\
\hline I & $30(14.9)$ \\
\hline$\|$ & $65(32.2)$ \\
\hline III & $48(23.7)$ \\
\hline IVa & $27(13.4)$ \\
\hline $\mathrm{IVb}$ & $25(12.3)$ \\
\hline Unknown & 7 (3.5) \\
\hline \multicolumn{2}{|l|}{ Adjuvant radiotherapy } \\
\hline Received & $144(71.3)$ \\
\hline Non received & $58(29.7)$ \\
\hline \multicolumn{2}{|l|}{ Type of radiotherapy } \\
\hline Conventional & $36 / 144(25)$ \\
\hline IMRT & $108 / 144(75)$ \\
\hline
\end{tabular}

$\begin{array}{lc}\begin{array}{l}\text { Concurrent chemotherapy } \\ \text { Received }\end{array} & 38 / 144(26.4) \\ \text { Non received } & 106 / 144(73.6) \\ \text { High-risk features } & \\ \mathrm{pT}_{\text {} / 4} & 27(13.4) \\ \mathrm{pN}_{\text {+ve }} & 72(36.9) \\ \mathrm{ECE}_{\text {, present }} & 31 / 72(43.1) \\ \text { Margins, positive } & 15(7.4) \\ \text { Margins, close } & 50(24.7) \\ \text { LVI, present } & 53(26.2) \\ \text { PNI, present } & 76(37.6) \\ \text { D0I (mm) } & \\ \leq 5 & 64(31.7) \\ 6-10 & 88(43.6) \\ >10 \text { and } \leq 20 & 46(22.7) \\ >20 & 4(2.0)\end{array}$

Values are presented as mean \pm standard deviation or number $(\%)$. ECE, extracapsular extension; LVI, Iymphovascular invasion; PNI, perineural invasion; DOI, depth of invasion; IMRT, intensity-modulated radiotherapy.

66.6, respectively (Fig. 2). Univariate analysis revealed that increasing $\mathrm{pT}$ stage, increasing $\mathrm{pN}$ stage, presence of $\mathrm{LVI}, \mathrm{DO}$ of $>20 \mathrm{~mm}$, and ECE were poor prognostic factors for OS. However, multivariate analysis using Cox proportional hazard ratios showed that increasing $\mathrm{pT}$ stage and the presence of ECE were significantly associated with a poorer OS (Table 3).

Majority of percent patients completed planned treatment. At the time of analysis, 74 patients (36.6\%) had developed recurrence. Of these, 33 patients (44.5\%) experienced tumor recurrence in the primary site alone, 23 (31.1\%) experienced recurrence in the nodal region alone, $3(4.0 \%)$ experienced recurrence in the primary site and nodal region, and 15 (20.2\%) had distant metastases most common being lung followed by bone.

\section{Discussion and Conclusion}

This study is an attempt to determine LRC and OS, failure pattern and explore various prognostic clinical and pathological factors influencing LRC and OS for OTSCC. This study continued to provide yet another evidence that locoregional recurrence remains a major mode of treatment failure in this subset of patients, considering approximately a third of recurrence being locoregional in this study. Hence, thorough attempt should be made to identify high-risk patients for recurrence based on clinical and pathological factors for whom additional therapy in the form of adjuvant 


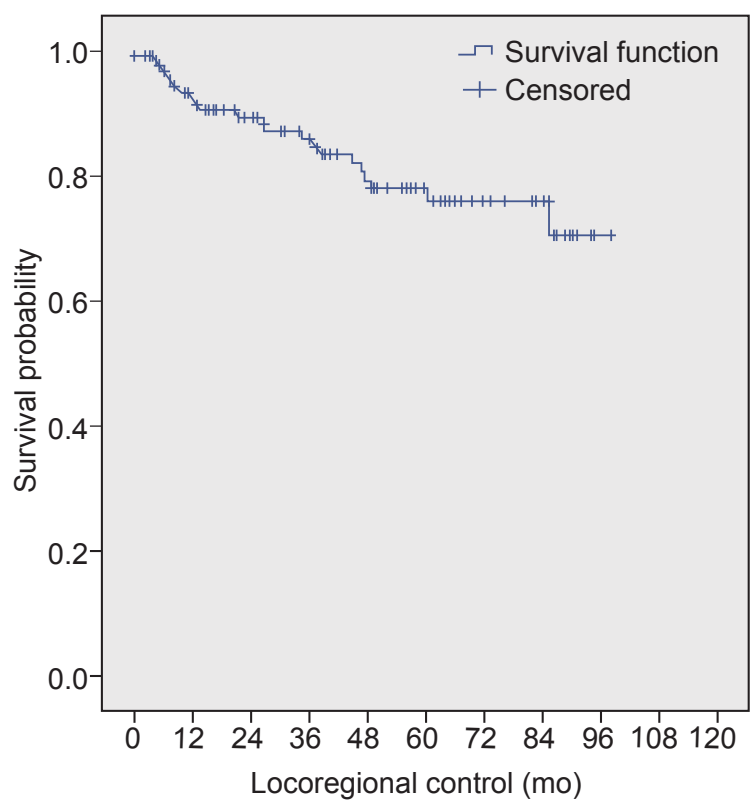

Fig. 1. Kaplan-Meier curve for locoregional control.

RT or CRT may improve outcomes.

Although there were $38.6 \%$ patients in the current study who were found to have pathological stage III/IV, more than two-thirds of patients from the entire cohort received adjuvant $\mathrm{RT}$ because of combination of other risk factors on surgical histopathological specimen examination. Approximately onefourth amongst those who received adjuvant RT also received concurrent chemotherapy (CCT).

Gender may have an influence on the treatment outcome as shown by various studies with large sample population including all subsites of oral cavity combined together [912]. These studies showed female gender being associated with better survival. The current study did not show any association with outcomes in line with Garavello et al. [13] who particularly looked at the influence of gender on OTSCC similar to our study, and found that gender does not influence prognosis in this subsite. Age whether as continuous or categorical variable was not found to affect outcome in OTSCC in this study. However in a Surveillance, Epidemiology and End Results database analysis, there was found to be a significant difference in median OS between age groups: 50-69 years and $\geq 70$ years with OTSCC (59.5 vs. 73.1 months, respectively); however the difference nullified when results were analysed after stage stratification [14]. Elderly patients tend to have multiple comorbidities which may influence the choice of therapy, intent of therapy, course of intensive treatment such as major surgeries or adjuvant CRT and may have poor

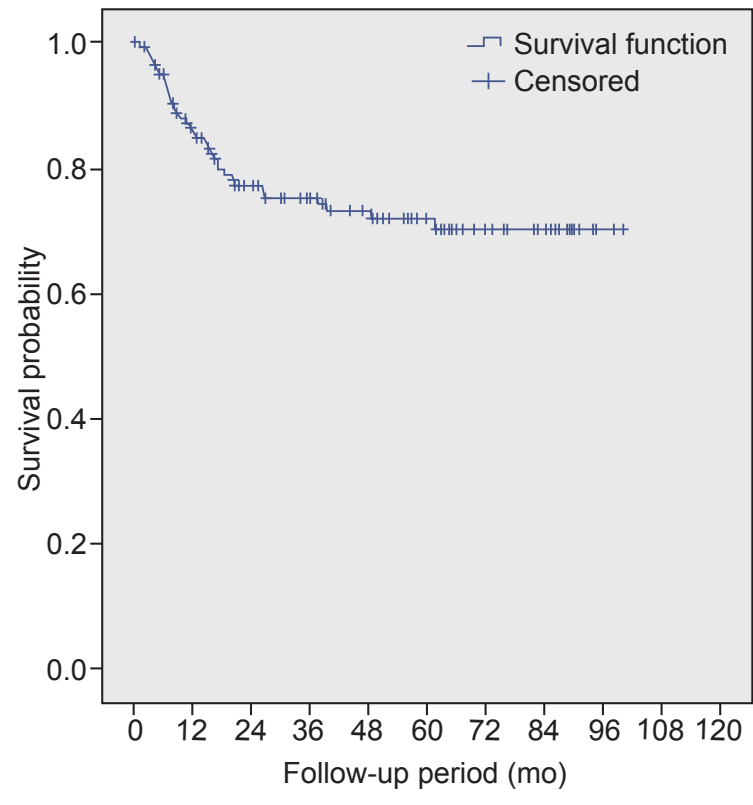

Fig. 2. Kaplan-Meier curve for overall survival.

tolerance to treatment, thereby showing different response to therapy. Thus, it appears that association of prognosis with age is complex and less clearly understood as yet in OTSCC.

A number of reports have showed that alcohol consumption and smoking are prognostic factor for head and neck cancer [15-18]. When looking at OTSCC per se, Sawabe et al. [19] in a prospective study showed that patients with OTSCC treated with surgery is associated with a significant inverse association between alcohol consumption and prognosis. However we did not find these habits be a prognostic factor in Indian population particularly looking at OTSCC. Our results are similar to that of a study done by Thiagarajan et al. [20] on similar cohort of patients as ours (Indian patients with OTSCC) that habits (including alcohol, smoking and tobacco chewing) does not affect the 0 .

In the OTSCC, T-stage and N-stage are independent indicators of the prognosis, although they are inter-related. Increasing size by T-stage leads to an increase in the rate of occult metastases [21-23], and increasing N-stage is associated with the development of distant metastases, particularly with multiple involvement or the presence of ECE [22]. Increasing PT stage emerged from our study as being of high prognostic value, as the risk of local recurrence at the time of diagnosis increased when tumour size increases from less than $2 \mathrm{~cm}$ to more than $4 \mathrm{~cm}$. The benefit in OS increased as the pT stage increased from T2 to T4. This experience is similar to results found in other reports [24]. 
Table 2. Univariate and multivariate analysis for locoregional control

\begin{tabular}{|c|c|c|c|c|}
\hline \multirow{2}{*}{ Variable } & \multicolumn{2}{|l|}{ Univariate } & \multicolumn{2}{|c|}{ Multivariate } \\
\hline & HR (95\% Cl) & $p$-value & HR (95\% Cl) & $p$-value \\
\hline Age (yr) & $1.652(0.476-2.067)$ & 0.415 & & \\
\hline$>50$ & Ref & & & \\
\hline$\leq 50$ & $0.603(0.466-1.209)$ & 0.771 & & \\
\hline \multicolumn{5}{|l|}{ Sex } \\
\hline Male & Ref & & & \\
\hline Female & $1.219(0.477-2.190)$ & 0.702 & & \\
\hline \multicolumn{5}{|l|}{ Addictions } \\
\hline No & Ref & & & \\
\hline Yes & $0.606(0.398-2.320)$ & 0.828 & & \\
\hline \multicolumn{5}{|l|}{ Grade } \\
\hline Well-differentiated & Ref & & & \\
\hline Moderately differentiated & $1.549(0.475-2.832)$ & 0.493 & & \\
\hline Poorly differentiated & $4.128(0.757-13.012)$ & 0.098 & & \\
\hline \multicolumn{5}{|l|}{ pT Stage } \\
\hline pT1 & Ref & & Ref & \\
\hline pT2 & $2.043(0.956-4.369)$ & 0.055 & $1.967(0.901-4.291)$ & 0.089 \\
\hline pT3 & $2.525(1.113-5.731)$ & 0.027 & $2.453(1.033-5.824)$ & 0.042 \\
\hline pT4 & 6.815 (2.184-21.269) & 0.001 & $5.029(1.207-20.950)$ & 0.027 \\
\hline \multicolumn{5}{|l|}{ pN Stage } \\
\hline pNO & Ref & & Ref & \\
\hline pN1 & $0.643(0.290-1.427)$ & 0.207 & $0.494(0.213-1.146)$ & 0.100 \\
\hline pN2 & $1.303(0.656-2.589)$ & 0.450 & $1.632(0.378-2.204)$ & 0.839 \\
\hline pN3 & $2.417(1.237-4.723)$ & 0.010 & $2.166(1.376-8.141)$ & 0.039 \\
\hline \multicolumn{5}{|l|}{ Margin } \\
\hline Adequate & Ref & & & \\
\hline Close & $2.073(0.743-3.630)$ & 0.642 & & \\
\hline Positive & $1.092(0.332-3.882)$ & 0.157 & & \\
\hline \multicolumn{5}{|l|}{ ECE } \\
\hline Absent & Ref & & Ref & \\
\hline Present & $5.773(3.091-8.653)$ & 0.005 & $3.086(1.268-4.400)$ & 0.018 \\
\hline \multicolumn{5}{|l|}{ LVI } \\
\hline Absent & Ref & & Ref & \\
\hline Present & 3.033 (1.112-5.533) & 0.017 & $1.274(0.725-2.240)$ & 0.400 \\
\hline \multicolumn{5}{|l|}{ PNI } \\
\hline Absent & Ref & & Ref & \\
\hline Present & $1.982(0.344-4.036)$ & 0.021 & $1.504(0.543-1.904)$ & 0.197 \\
\hline \multicolumn{5}{|l|}{ DOI (mm) } \\
\hline$\leq 5$ & Ref & & & \\
\hline $6-10$ & $1.192(0.678-2.097)$ & 0.542 & & \\
\hline$>10$ and $\leq 20$ & $1.427(0.747-2.729)$ & 1.427 & & \\
\hline$>20$ & 3.826 (0.492-29.751) & 0.200 & & \\
\hline \multicolumn{5}{|l|}{ Type of radiotherapy } \\
\hline IMRT & Ref & & & \\
\hline Conventional & $0.623(0.387-3.77)$ & 0.766 & & \\
\hline
\end{tabular}

$H R$, hazard ratio; Cl, confidence interval; ECE, extracapsular extension; LVI, lymphovascular invasion; PNI, perineural invasion; DOI, depth of invasion; IMRT, intensity-modulated radiotherapy. 
Table 3. Univariate and multivariate analysis for overall survival

\begin{tabular}{|c|c|c|c|c|}
\hline \multirow{2}{*}{ Variable } & \multicolumn{2}{|l|}{ Univariate } & \multicolumn{2}{|l|}{ Multivariate } \\
\hline & $\mathrm{HR}(95 \% \mathrm{Cl})$ & p-value & $\mathrm{HR}(95 \% \mathrm{Cl})$ & $p$-value \\
\hline Age (yr) & $1.328(0.768-2.297)$ & 0.310 & & \\
\hline$>50$ & Ref & & & \\
\hline$\leq 50$ & $0.997(0.977-1.018)$ & 0.805 & & \\
\hline \multicolumn{5}{|l|}{ Sex } \\
\hline Male & Ref & & & \\
\hline Female & $1.007(0.546-1.855)$ & 0.983 & & \\
\hline \multicolumn{5}{|l|}{ Addictions } \\
\hline No & Ref & & & \\
\hline Yes & $0.918(0.536-1.573)$ & 0.755 & & \\
\hline \multicolumn{5}{|l|}{ Grade } \\
\hline Well-differentiated & Ref & & & \\
\hline Moderately differentiated & $1.288(0.659-2.517)$ & 0.460 & & \\
\hline Poorly differentiated & $3.242(0.898-11.706)$ & 0.073 & & \\
\hline \multicolumn{5}{|l|}{ pT Stage } \\
\hline pT1 & Ref & & Ref & \\
\hline pT2 & $5.467(1.302-22.956)$ & 0.020 & 6.061 (1.294-28.385) & 0.022 \\
\hline pT3 & 7.605 (1.762-32.815) & 0.007 & $14.876(2.668-82.945)$ & 0.002 \\
\hline pT4 & 25.505 (5.062-128.510) & 0.000 & 16.809 (2.053-137.644) & 0.009 \\
\hline \multicolumn{5}{|l|}{ pN Stage } \\
\hline pNo & Ref & & Ref & \\
\hline $\mathrm{pN} 1$ & $1.650(0.731-3.725)$ & 0.228 & $1.025(0.420-2.499)$ & 1.025 \\
\hline $\mathrm{pN} 2$ & $2.308(1.021-5.215)$ & 0.044 & $1.184(0.426-3.292)$ & 0.747 \\
\hline pN3 & $6.942(3.627-13.288)$ & 0.000 & $4.268(0.873-27.047)$ & 0.070 \\
\hline \multicolumn{5}{|l|}{ Margin } \\
\hline Adequate & Ref & & & \\
\hline Close & $1.095(0.592-2.026)$ & 0.772 & & \\
\hline Positive & $1.725(0.592-2.026)$ & 0.258 & & \\
\hline \multicolumn{5}{|l|}{ ECE } \\
\hline Absent & Ref & & Ref & \\
\hline Present & $4.154(2.359-7.314)$ & 0.000 & $3.085(1.214-5.498)$ & 0.028 \\
\hline \multicolumn{5}{|l|}{ LVI } \\
\hline Absent & Ref & & Ref & \\
\hline Present & $2.392(1.393-4.107)$ & 0.002 & $1.665(0.911-3.044)$ & 0.098 \\
\hline \multicolumn{5}{|l|}{ PNI } \\
\hline Absent & Ref & & & \\
\hline Present & $1.604(0.930-2.769)$ & 0.090 & & \\
\hline \multicolumn{5}{|l|}{ DOI (mm) } \\
\hline$\leq 5$ & Ref & & Ref & \\
\hline $6-10$ & 1.585 (0.799-3.143) & 0.187 & $0.872(0.404-1.880)$ & 0.726 \\
\hline$>10$ and $\leq 20$ & $1.455(0.653-3.243)$ & 0.359 & $1.285(0.096-2.839)$ & 0.323 \\
\hline$>20$ & $11.045(2.298-53.073)$ & 0.030 & $2.013(0.253-15.992)$ & 0.508 \\
\hline \multicolumn{5}{|l|}{ Type of radiotherapy } \\
\hline IMRT & Ref & & & \\
\hline Conventional & $0.991(0.481-2.040)$ & 0.980 & & \\
\hline
\end{tabular}

HR, hazard ratio; $\mathrm{Cl}$, confidence interval; ECE, extracapsular extension; LVI, lymphovascular invasion; PNI, perineural invasion; DOI, depth of invasion; IMRT, intensity-modulated radiotherapy. 
Presence of cervical lymphadenopathy is shown as single most important clinical predictor of OS in this study. However, mere presence of single node less than $3 \mathrm{~cm}$ did not affect OS, it was the presence of multiple nodes which affected OS significantly poorly. There were no patients with clinical N3 stage because surgeons found them to be unresectable, and hence were given radical RT/CRT. There were no patients who were upstaged to pN3 stage either. All patients received CCT in this study if there were ECE. This was based on the combined analysis of landmarks trials EORTC-22931 and RTOG-9501 studies which showed advantage of adding CCT [25]. Despite adding CCT in the presence of ECE in our study patients, it still continued to show significant impact on OS on multivariate analysis. When looking particularly at OTSCC high quality data is sparse regarding the impact of ECE. Our results are consistent with few retrospective studies which showed ECE as a significant predictor of OS in OTSCC $[20,26,27]$.

DOI is used as a surrogate for risk of lymphatic involvement. Hence, neck dissection (elective neck dissection) has become an acceptable neck management strategy for OTSCC when the DOI is high $[28,29]$. Most centers regard 3.0 to $4.0 \mathrm{~mm}$ as the optimal cutoff for DOl, beyond which neck management is essential for the clinically node-negative neck. There has been considerable controversy regarding the need for adjuvant RT in patients without high-risk features, except for a DOI of $>4.0 \mathrm{~mm}$. Following the results published by Ganly et al. [30], from the Memorial Sloan Kettering Cancer Center and Princess Margaret Hospital in 2013, which demonstrated much higher regional failure than anticipated in patients with $\mathrm{pT} 1 / 2$ and pNO OSCC, who underwent partial glossectomy and ipsilateral elective neck dissection without postoperative RT, our institution has accepted a DOI of $>4.0 \mathrm{~mm}$ alone as a sufficient risk factor to offer adjuvant RT in the majority of these cases, although it influenced OS in this study in univariate analysis only when it was $>20 \mathrm{~mm}$. Few other studies have used multivariate analysis to substantiate the importance of the DOI in OTSCC or have revealed a correlation between the DOI and LRC or disease-free survival [31-33]. A recent study by Gokavarapu et al. [34] showed that postoperative RT did not influence LRC or OS in a subset of patients with $\mathrm{pT} 1 / 2$ and $\mathrm{pNO}$ OSCC with a DOI of $\geq 4.0 \mathrm{~mm}$. Although it appears certain that $\mathrm{DOI}$ has prognostic role for OCSCC, it is yet to be evaluated beyond which $\mathrm{DOI}$ in $\mathrm{mm}$ adjuvant RT benefit significantly.

LVI has been shown to be significantly associated with tumor site, diameter, and thickness, PNI, the invasive front, the pattern of invasion, lymph node metastasis, resection margin status, local recurrence, and survival [22,35-37]. Consistent with these findings, our study showed a significant association between LVI and OS in the univariate analysis. However, in the multivariate analysis, LVI was not found to be an independent predictor of OS. A review of the literature identified only one study that reported LVI to be significant in the multivariate analysis. Rahima et al. [38] discussed the possibility of using this parameter as a criterion to define aggressiveness and to select patients for more specific and aggressive treatment in the future.

In the analysis by El-Husseiny et al. [39] on OTSCC (T1-4 N0-3) the reported 5-year OS was 65\%. Rusthoven et al. [7] described a 5 -year OS of $60.9 \%$ in patients treated for T1-2 NO OTSCC. Although the prognosis of OTSCC was poorer than that of cancers in other oral cavity sites, in this study, the 5-year OS and LRC were shown as $66.6 \%$ and $58.3 \%$, respectively. This study showed the survival outcome of OTSCC to be affected by increasing $T$ stage, more than two clinically positive nodes, ECE of lymph node metastasis and LVI on univariate analysis. These findings have also been reported by others [24,40-42]. However, multivariate analysis revealed increasing PT stage and presence of ECE to be significantly associated with overall survival.

The limitations of this study include potential bias associated with its retrospective design. Although the treatment guidelines followed at our institute are standardized, some differences remain in the indications of adjuvant therapy in OCSCC depending on individual experiences of the treating oncologist, especially with regards to DOI. A strength of this study is its large cohort of patients with squamous cell carcinoma limited to oral tongue subsite only, taken from one of the largest and most exclusive cancer research centers in the country. Furthermore, the fact that all surgical and histopathological reporting was done at a single institute may have helped to reduce bias.

In conclusion, locoregional failure remains the main cause of treatment failure in resectable OTSCC. There is scope to further improve prognosis considering modest LRC and OS. Pathological T-stage, $\mathrm{N}$-stage, and ECE are strong prognostic factors. Further research is required to confirm whether adjuvant therapy adds to treatment outcomes in cases with $\mathrm{LVI}, \mathrm{PNI}$ and DOI, and help clinicians tailoring adjuvant therapy.

\section{Conflict of Interest}

No potential conflict of interest relevant to this article was reported. 


\section{References}

1. Myers JN, Elkins T, Roberts D, Byers RM. Squamous cell carcinoma of the tongue in young adults: increasing incidence and factors that predict treatment outcomes. Otolaryngol Head Neck Surg 2000;122:44-51.

2. Annertz K, Anderson H, Biorklund $A$, et al. Incidence and survival of squamous cell carcinoma of the tongue in Scandinavia, with special reference to young adults. Int J Cancer 2002;101:95-9.

3. Shiboski CH, Schmidt BL, Jordan RC. Tongue and tonsil carcinoma: increasing trends in the U.S. population ages 2044 years. Cancer 2005;103:1843-9.

4. Fein DA, Mendenhall WM, Parsons JT, et al. Carcinoma of the oral tongue: a comparison of results and complications of treatment with radiotherapy and/or surgery. Head Neck 1994;16:358-65.

5. Lefebvre $J$, Coche-Dequeant $B$, Buisset $E$, Mirabel $X$, Van $J T$, Prevost B. Management of early oral cavity cancer: experience of Centre Oscar Lambret. Eur J Cancer B Oral Oncol 1994;30B:216-20.

6. Lapeyre M, Bollet MA, Racadot S, et al. Postoperative brachytherapy alone and combined postoperative radiotherapy and brachytherapy boost for squamous cell carcinoma of the oral cavity, with positive or close margins. Head Neck 2004;26:216-23.

7. Rusthoven $K$, Ballonoff $A$, Raben D, Chen C. Poor prognosis in patients with stage I and II oral tongue squamous cell carcinoma. Cancer 2008;112:345-51.

8. Cheng YJ, Tsai MH, Chiang CJ, et al. Adjuvant radiotherapy after curative surgery for oral cavity squamous cell carcinoma and treatment effect of timing and duration on outcome-A Taiwan Cancer Registry national database analysis. Cancer Med 2018 Jun 14 [Epub]. http://doi.org/10.1002/cam4.1611.

9. Micheli A, Mariotto A, Giorgi Rossi A, Gatta G, Muti P. The prognostic role of gender in survival of adult cancer patients. EUROCARE Working Group. Eur J Cancer 1998;34(14 Spec No):2271-8.

10. Funk GF, Karnell LH, Robinson RA, Zhen WK, Trask DK, Hoffman HT. Presentation, treatment, and outcome of oral cavity cancer: a National Cancer Data Base report. Head Neck 2002;24:165-80.

11. Franco EL, Dib LL, Pinto DS, Lombardo V, Contesini H. Race and gender influences on the survival of patients with mouth cancer. J Clin Epidemiol 1993;46:37-46.

12. Listl $S$, Jansen $L$, Stenzinger $A$, et al. Survival of patients with oral cavity cancer in Germany. PLoS One 2013:8:e53415.

13. Garavello W, Spreafico R, Somigliana E, Gaini L, Pignataro L, Gaini RM. Prognostic influence of gender in patients with oral tongue cancer. Otolaryngol Head Neck Surg 2008;138:768-71.

14. Bhattacharyya N. A matched survival analysis for squamous cell carcinoma of the head and neck in the elderly. Laryngoscope 2003;113:368-72.

15. Leoncini E, Vukovic V, Cadoni G, et al. Clinical features and prognostic factors in patients with head and neck cancer: results from a multicentric study. Cancer Epidemiol 2015;39:367-74

16. Li Y, Mao Y, Zhang $Y$, et al. Alcohol drinking and upper aerodigestive tract cancer mortality: a systematic review and meta-analysis. Oral Oncol 2014;50:269-75.

17. Inoue M, Nagata C, Tsuji I, et al. Impact of alcohol intake on total mortality and mortality from major causes in Japan: a pooled analysis of six large-scale cohort studies. J Epidemiol Community Health 2012;66:448-56.

18. Kim MK, Ko MJ, Han JT. Alcohol consumption and mortality from all-cause and cancers among 1.34 million Koreans: the results from the Korea national health insurance corporation's health examinee cohort in 2000. Cancer Causes Control 2010;21:2295-302.

19. Sawabe M, Ito $H_{1}$ Oze I, et al. Heterogeneous impact of alcohol consumption according to treatment method on survival in head and neck cancer: a prospective study. Cancer Sci 2017;108:91-100.

20. Thiagarajan S, Nair S, Nair D, et al. Predictors of prognosis for squamous cell carcinoma of oral tongue. J Surg Oncol 2014;109:639-44.

21. Kirita T, Ohgi K, Shimooka H, et al. Preoperative concurrent chemoradiotherapy plus radical surgery for advanced squamous cell carcinoma of the oral cavity: an analysis of long-term results. Oral Oncol 1999;35:597-606.

22. Jones HB, Sykes $A$, Bayman $N$, et al. The impact of lymphovascular invasion on survival in oral carcinoma. Oral Oncol 2009;45:10-5.

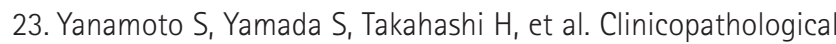
risk factors for local recurrence in oral squamous cell carcinoma. Int J Oral Maxillofac Surg 2012;41:1195-200.

24. Lin CY, Wang HM, Kang CJ, et al. Primary tumor site as a predictor of treatment outcome for definitive radiotherapy of advanced-stage oral cavity cancers. Int J Radiat Oncol Biol Phys 2010;78:1011-9.

25. Bernier J, Cooper JS, Pajak TF, et al. Defining risk levels in locally advanced head and neck cancers: a comparative analysis of concurrent postoperative radiation plus 
chemotherapy trials of the EORTC (\#22931) and RTOG (\#9501) Head Neck 2005;27:843-50.

26. Myers JN, Greenberg JS, Mo V, Roberts D. Extracapsular spread: a significant predictor of treatment failure in patients with squamous cell carcinoma of the tongue. Cancer 2001;92:3030-6.

27. Metcalfe $E$, Aspin L, Speight $R$, et al. Postoperative (chemo) radiotherapy for oral cavity squamous cell carcinomas: outcomes and patterns of failure. Clin Oncol (R Coll Radiol) 2017;29:51-9.

28. Fukano H, Matsuura H, Hasegawa $Y$, Nakamura S. Depth of invasion as a predictive factor for cervical lymph node metastasis in tongue carcinoma. Head Neck 1997;19:205-10.

29. Al-Rajhi N, Khafaga Y, El-Husseiny J, et al. Early stage carcinoma of oral tongue: prognostic factors for local control and survival. Oral Oncol 2000;36:508-14.

30. Ganly I, Goldstein D, Carlson DL, et al. Long-term regional control and survival in patients with "low-risk," early stage oral tongue cancer managed by partial glossectomy and neck dissection without postoperative radiation: the importance of tumor thickness. Cancer 2013;119:1168-76.

31. 0-charoenrat P, Pillai G, Patel $S$, et al. Tumour thickness predicts cervical nodal metastases and survival in early oral tongue cancer. Oral Oncol 2003;39:386-90.

32. Spiro RH, Huvos AG, Wong GY, Spiro JD, Gnecco CA, Strong EW. Predictive value of tumor thickness in squamous carcinoma confined to the tongue and floor of the mouth. Am J Surg 1986;152:345-50.

33. Larsen SR, Johansen J, Sorensen JA, Krogdahl A. The prognostic significance of histological features in oral squamous cell carcinoma. J Oral Pathol Med 2009;38:657-62.
34. Gokavarapu S, Parvataneni N, Rao S LM, Reddy R, Raju KV Chander $\mathrm{R}$. Role of postoperative radiation therapy (PORT) in PT1-T2 NO deep tongue cancers. Oral Surg Oral Med Oral Pathol Oral Radiol 2015;120:e227-31.

35. Sparano A, Weinstein G, Chalian A, Yodul M, Weber R. Multivariate predictors of occult neck metastasis in early ora tongue cancer. Otolaryngol Head Neck Surg 2004;131:472-6.

36. Binmadi NO, Basile JR. Perineural invasion in oral squamous cell carcinoma: a discussion of significance and review of the literature. Oral Oncol 2011;47:1005-10.

37. Fagan JJ, Collins B, Barnes L, D'Amico F, Myers EN, Johnson JT. Perineural invasion in squamous cell carcinoma of the head and neck. Arch Otolaryngol Head Neck Surg 1998;124:637-40.

38. Rahima B, Shingaki S, Nagata M, Saito C. Prognostic significance of perineural invasion in oral and oropharyngea carcinoma. Oral Surg Oral Med Oral Pathol Oral Radiol Endod 2004;97:423-31.

39. El-Husseiny G, Kandil $A$, Jamshed $A$, et al. Squamous cell carcinoma of the oral tongue: an analysis of prognostic factors. Br J Oral Maxillofac Surg 2000;38:193-9.

40. Kalnins IK, Leonard AG, Sako K, Razack MS, Shedd DP. Correlation between prognosis and degree of lymph node involvement in carcinoma of the oral cavity. Am J Surg 1977;134:450-4.

41. Woolgar JA, Rogers SN, Lowe D, Brown JS, Vaughan ED. Cervical lymph node metastasis in oral cancer: the importance of even microscopic extracapsular spread. Oral Oncol 2003:39:130-7.

42. Grandi C, Alloisio M, Moglia D, et al. Prognostic significance of lymphatic spread in head and neck carcinomas: therapeutic implications. Head Neck Surg 1985;8:67-73. 